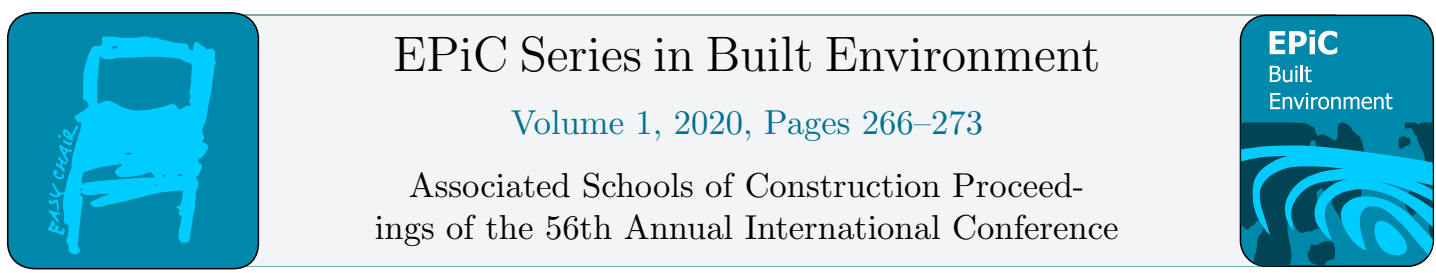

\title{
The public perception of prefabricated housing in the UK
}

\author{
Raj Shah, PhD, FHEA; Leigh O’Mahony, PhD Student; Wilfred Matipa, PhD, FHEA; \\ and Prof. Alison Cotgrave, PhD, SFHEA \\ Department of the Built Environment, Faculty of Engineering and Technology, Liverpool \\ John Moores University, Liverpool, England, UK
}

The UK has been in a housing crisis for many years and it has missed its house building targets by over 1.3 million houses since 2004. Something needs to change to achieve government target. Prefabricated homes could be a solution to this issue since they could bring overall construction duration down, keep the costs lower and provide higher quality homes as they are produced in a controlled factory environment rather than on site and open to other elements. However, many controlling factors such as higher initial investment, incomplete industry supply chain and public perception have had a major impact on their limited usage up to this point. The aim of this paper is to examine the public perception regarding the prefabricated housing in the UK using a mixed research methodology with the questionnaire survey. There has been limited research in this area and the majority of research has focused on the technology involved and the sustainability impact of prefabricated housing. The survey results reveal that the UK public can struggle to accept a prefabricated house due to the lack of information regarding prefabricated housing. A common belief is that the UK government needs to support this type of housing with a financing package to encourage them to buy the prefabrication houses and builders need to inject more houses in market.

Key Words: Prefabricated, Perception, Public, Housing, UK, Delivery, Quality, Economical

\section{Introduction}

The current housing situation in the UK is one that has been going on for multiple years; it includes ambitious government targets, an appetite to build and a large amount of people in need of housing. However, the UK continue to have a housing crisis as the average amount of homes built each year since the 1970's has been 160,000 when to keep up with population growth and tackle under-supply an additional 100,000 per year need building (Department for Communities and Local Government, 2017). Added to this additional problems are coming to fruition and a perfect storm appears to be happening in the sector due to an ageing workforce, a lack of new entrants to the field and growing restrictions on free movement of labor across Europe due to the impending Brexit. There were 12,000 small house builders in 1988 accounting for the building of one in four homes; but by 2017, this had dropped to 2,500 that were responsible for only 12 per cent of new builds (House Builders Federation, 2017)

T. Leathem (ed.), ASC 2020 (EPiC Series in Built Environment, vol. 1), pp. 266-273 
A famous saying has always been to build your way out of recession, given that, the building industry has always been at the forefront of helping the UK get out of a crisis. However, this is a housing crisis; an uncomfortable truth for the UK is that relying on Traditional housing methods will not halt it (Henderson, 2018). The Government and industry need to think outside the box as currently demand is far outstripping supply in the industry, which is clearly shown by the house prices in the UK. They are still rising, and fast. According to the Office for National Statistics (ONS) in June 2018, the average price for a house in the UK was $£ 214,000$. Before the pre-economic downturn peak in September 2007, when price was $£ 190,000$. Nothing appears to be halting this juggernaut, even, worries over the impending Brexit has not stopped an increase in house prices.

The ONS has been quoted as saying house prices annual growth has increased to 5.6\% in August 2017 from $5.2 \%$ in July 2017. This is no new trend as growth has been rampant over the past decade, seeing the average cost of a house increased by $50 \%$ over this timeframe. Farmer (2016) essentially classified the UK construction industry as a 'dying patient'. Years later, that diagnosis appears to have not changed and the patient still appears to be hospitalized. There is still no answer to the housing crisis, productivity is still low, and a lack of innovation is very apparent in the industry as a whole. The collapse of the Major international firm Carillion at the start of 2018 is a looking glass into just how fragile the situation is. During an event in 2017, Farmer commented, "the industry is standing on a burning platform and all other options have gone. It simply has to change" (Easen, 2018). The government and house builders are looking for solutions and prefabricated housing is being touted as a major step in the right direction. Innovation in the industry has been coming from SME's, however one of the biggest challenges they face in the sector is the spread of expertise (Mlecnik, 2013).

\section{Literature Review}

Public perception is a concept that sits somewhere between the truth and opinion given that it is a person's reality shaped from facts they know blended with popular opinion, media coverage and reputation; It is a common trend that is seen throughout life from politics to football and from picking a school to buying a car. Quite often, a negative public perception is hard to overcome, however it can be possible. A classic example would be the car firm Skoda. In the early 1990's they never had a great reputation in the UK; often cited in jokes regarding quality and reliability. However, after an ingenious marketing campaign, including ground, breaking adverts and having their cars compete at the highest levels in motorsports; the general perception of the company flip-flopped and they are known as a safe and fast reliable car manufacturer.

Public perception should not base on something other than facts or the truth and will not always be inaccurate, as people do have access to a wide range of information on a host of subjects and will not always rely upon hearsay, rumors or other opinions. However, there are times when cultural bias, upbringing or prejudice can have a bearing on that opinion. Public perception can also be unrealistically positive or negative and this can have long-term implications when the truth emerges, as people will need to adapt or continue to be entrenched in a faux reality. Public perceptions matter, as they can literally be the difference between success and failure (Granger-Morton, 1997).

Very few studies have looked into the public perception of prefabricated housing. Many studies concentrate on the technological benefits of a building, its sustainability or its lifespan, which all bring great benefits to the industry. One type of study that gets the perception of a building whilst in use is a post-occupancy evaluation (POE). McGrath and Horton (2011) investigated MMC student accommodation in the UK using a POE on the people residing in the hall. The findings show peoples biggest worries concerned noise levels, however only $15 \%$ percent of those who commented thought 
that was due to the building itself. This study cannot be taken as a flag bearer for prefabricated buildings having minimal worries with noise though as the target group was relatively small and many had limited understanding of Building typologies and had to have it explained, added to that common complaints from student halls are noise based leaving it hard to fully contextualize.

The HOME group commissioned a survey by YouGov to find out the public perception of modular homes. It managed to gain the opinions of over 2000 people from across the UK. The standout information gained about modular homes were that many of the public failed to recognize many modern types. Nearly half the people surveyed believed that modular homes are less durable than those that use traditional methods (HOME group, 2018). However, Booth (2017) offered an argument that differs from the perception, which states, "When people question the quality of a prefabricated house an argument can be made that 100 workers on an indoor production line will bring more quality than the same amount on a muddy building site out in the elements". Past researcher such as Nanyam et al 2017, Steinhardt and Manley 2016, Švajlenka and Kozlovská 2018, backs up above statement.

\section{Research Methodology}

The study adopted a mixed research methodology using a questionnaire survey. Initial research was desk-based study and literature review where an understanding of historical views and the current state of play of prefabricated housing investigated. From this research, knowledge gaps appeared and questions were formed to gain rich data sets that would go some way to filling them. The research data was collected by designing the questionnaire survey and conducted using online survey tools. The questionnaire comprised of a mixture of open and closed questions. It was considered to be the best type of research that could reach the largest amount of people, generating statistical and rich data in the limited time period available. This research takes a mixed method approach as it takes into account several aspects of public perception. This type of methodology allowed for the combined strengths of both qualitative and quantitative to gain the best outcome. It allowed pictures and narratives to be teamed up with numbers and allowed a broader range of questions as it is not confined within the boundaries of one methodology, ultimately ending up complementary. It helps to gather wide knowledge, informing about practices and current theory. As this was non-funded research, the sampling method used is non-probability voluntary and random sampling method. While it has limitations, it is the best approach under existing circumstances. It is also the best and the fastest way of collecting the data sets needed for the research required. The people targeted for this survey were potential house buyers over the age of 18 and currently residing in the UK.

\section{Data Collection and Analysis}

The questionnaire survey was targeted around 500 samples randomly to the selected people who fitted the criteria adopted for the research. From 235 responses (47\% response rate), only 195 deemed eligible for use in analyzing the research data, as they agreed to initial security questions and fully completed the questionnaire. There was a good spread of age and genders amongst the respondents and every area of the UK was represented. Existing living circumstance was also taken into account, as shown in the figures 1 to 4 below. 


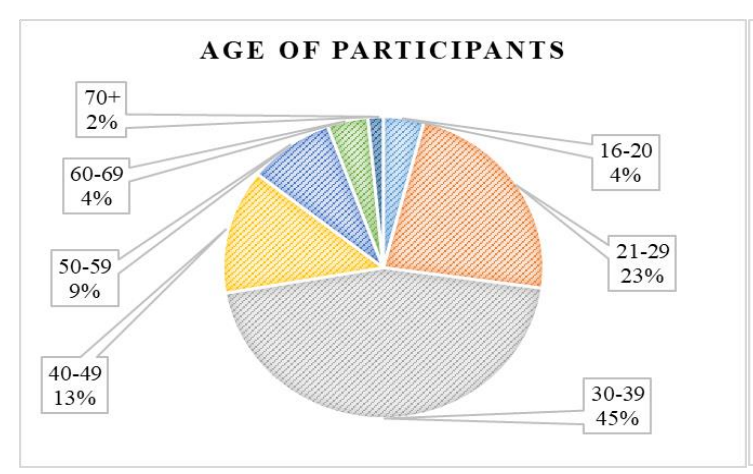

Figure 1. Age range

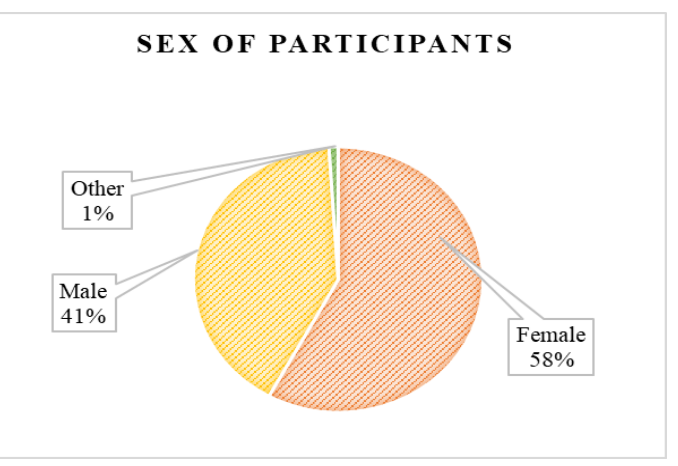

Figure 2. Gender



Figure 3. Location of participants
LIVING SITUATION

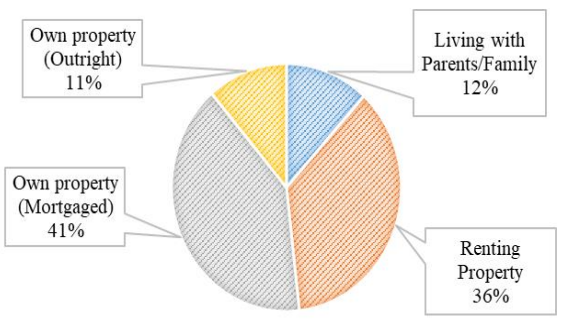

Figure 4. Living situations

\section{Headlines from results}

- Most people, who are unsure or do not like to own a prefabricated property, put it down to a lack of information available.

- The majority of people wanting to buy a prefabricated would do so because it was cheaper.

- There is little generation bias when it comes to buying a prefabricated home.

- Help with financing is considered as the best way the government could encourage more people into buying a prefabricated home.

\section{Results Discussion}

The historical views of the prefabricated housing were not overly prevalent in data collected; however, five people did quote it as a reason why they were not sure if they would buy a prefabricated house and one person having lived in a post war prefabricated home discounted buying a new type prefabricated house. While they are quite low numbers in the scheme of things, just under $3 \%$ of respondents, it is quite significant that they gave that one reason. In addition, some other reasons given may have been attributed to the post war houses given the quality concerns and the longevity worries $(13 \%$ of respondents), see table 1. 
Table 1: Answers and reasoning to "Would you live in a prefabricated house?"

\begin{tabular}{|c|c|c|c|c|c|}
\hline Yes & & No & & Maybe & \\
\hline Cheaper & 25 & Prefer traditional & 7 & More information needed & 32 \\
\hline Experience & 12 & Longevity & 6 & Quality concern & 13 \\
\hline Likes & 10 & Quality concern & 6 & Situation & 7 \\
\hline Time, cost, quality & 7 & Solidity worries & 4 & Previous incarnation & 5 \\
\hline Efficiency & 7 & Lack of character & 3 & Not sure & 5 \\
\hline Quality & 6 & Wrong style & 3 & Cost & 5 \\
\hline Faster & 5 & Lack of information & 3 & Appearance & 3 \\
\hline Innovative & 4 & Maintenance concerns & 2 & Mortgage difficulties & 3 \\
\hline Choices & 3 & Transportation & 1 & Land concerns & 2 \\
\hline Flexibility & 1 & Previous experience & 1 & Longevity & 1 \\
\hline Enjoyable & 1 & Too standardised & 1 & Quite interested & 1 \\
\hline Total & 81 & Total & 37 & Total & 77 \\
\hline
\end{tabular}

About the supply and demand theory, the questionnaire never asked direct questions, as it was covered in the secondary research. This could have been an oversight. However, in the feedback section for "reason you have made your choice concerning buying a prefabricated house" two responses were noted as follows:

Statement 1: "For me I would be looking to get onto the property ladder by any means necessary at this stage. If prefabricated homes are cheaper and more convenient to assemble, and as a first-time buyer I could reap those benefits through taking out a smaller mortgage, I'd have no issue buying one". The first statement shows that a person desperate to get on to the property ladder and would enjoy the benefits offered by a prefabricated home. Statement 2: "I've seen them work in other countries and as they are prefabricated they take less time to erect and cost considerably less, making them more affordable than the current market." The second respondent statement reflects the value of prefabricated housing built in other countries and agreed that such housing would be beneficial to the UK.

An overwhelming majority of people gave their positive reason for buying a prefabricated house, as they can be cheaper than traditional housing. According to the current housing market, there is no surprise that around $27 \%$ of the people would be interested to buy a prefabricated house with agreed above reasons. In general, $87 \%$ of the people who wanted to own a prefabricated house did so because of a benefit linked to the type of house, be that it is quicker to build, cheaper, more efficient, flexible or more innovative. To gain an insight into the publics visual association of their expectations of what a prefabricated house looks like, a set of pictures showing prefabricated housing were displayed asking the public if they thought it was a prefabricated house or not. The results are presented below.
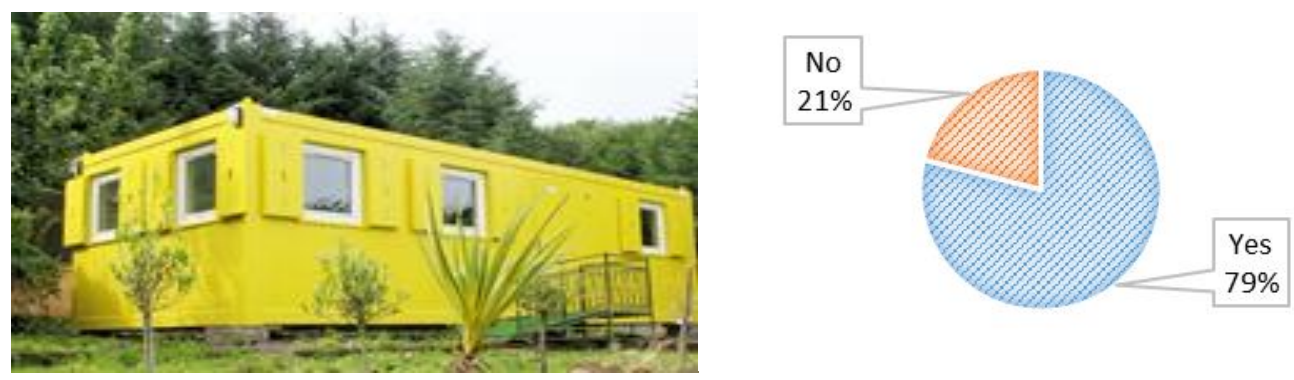



Figure 5. Results for picture survey "Is this a prefabricated house?"

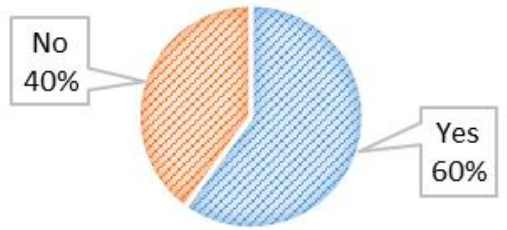




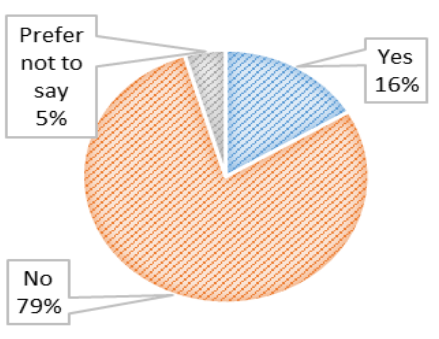

Figure 6. Purchase without Mortgage

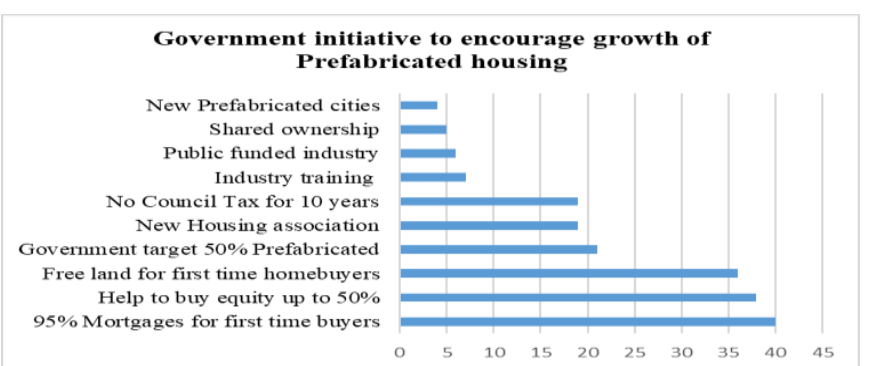

Figure 7. Potential government schemes

The survey enlarged an insight into public perception of prefabricated housing. The pictures of prefabricated houses people guessed right on average $54 \%$ of the time. However, prefabricated house 5 had $86.3 \%$ of respondents guess the wrong answer (see figure 5). Perhaps there is further investigation to have into the reasons behind this. That was in contrast to prefabricated house number 1 , where almost $80 \%$ correctly identified it as a prefabricated home. This was due to the nature and style. The question regarding available finance for a prefabricated house was insightful. Using the minimum amount a person may be expected to put up to buy a prefabricated outright showed that the large majority of people (78\%) wouldn't be in with a chance of being able to purchase without a mortgage, which is one of the reasons the industry is being held back (see figure 6). Added to this the question about what people thought the government should do $44.3 \%$ of people thought that the government should help with financing either through $95 \%$ mortgages, shared ownership or help to buy equity loans (figure 4).

\section{Conclusion}

The prefabricated housing could have a massive impact on changing the current paradigm in the UK housing industry however; it is not currently on course to do so. The industry feels like it is a coiled spring waiting to be released, but it has to wait for the first major play. The UK Government probably holds the key to starting a renaissance in housebuilding with several key things they could implement. If the government goes through their planned legislation on environmental and energy policy, it is assumed that the industry would grow exponentially as it would encourage firms to build more factories and increase their housing supply. Public perception has increasingly improved and this will continue to improve since the exposure to modern methods of prefabrication is becoming the normal. While the historical views of prefabricated housing are still there with some people, this perception appears to be declining; however, a large misunderstanding is still present in the public.

Moreover, the industry is at the point where it has no other option but to change; due to the huge demand on houses and the limitations of its current supply, which can be in part put down to Brexit and an ageing workforce. The benefits of prefabricated housing far outstrip the negatives. They are faster to build, have a higher build quality and low cost to build due to the manufacturing process in comparison to traditional methods. This means more units can be built on sites for cheaper and with less snag defects and high productive rate. Hence, the prefabricated will be compliment of traditional building not to replace it. Supply chains appear to be willing to adapt to the requirements needed to make prefabricated housing construction work to the best of its abilities, that coupled with innovative practices by companies can only be seen as a positive. The financial sector needs to support in adoption to make prefabricated housing a regular property to mortgage rather than as it is currently seen. Government legislation or input could change this way of thinking. Overall, the perception of prefabricated housing in the UK is improving however; people still need more exposure and understanding to change it and to put it at least on par with traditional housebuilding methods. 


\section{References}

Booth, R. (2017). The Guardian Newspaper article about the UK house builders. [Online] available at https://www.theguardian.com/business/2017/dec/31/uk-housebuilders-factories-prefabricating-homes, [Accessed: 06 10, 2019].

Bulmer, J. (2018). Infrastructure Intelligence. Available online at http://www.infrastructureintelligence.com/article/may-2018/four-ways-help-solve-housing-crisis. [Accessed: 06-102019]

Department for Communities and Local Government. (2017) Fixing our broken housing market [Online] Available at: https://www.gov.uk/government/publications/fixing-our-broken-housingmarket [Accessed: 12-12-19]

Duc, E., Forsythe, P. \& Orr, K. (2014). Is there really a case for Off-Site Manufacturing? Sydney, ISARC, $31^{\text {st }}$ International Symposium on Automation and Robotics in Construction and Mining.

Easen, N. (2018). Modular homes are the future of UK housing. [Online] Available at https://www.raconteur.net/business-innovation/modular-homes-future-housing. [Accessed: 16-10-2019]

Farmer, M. (2016) The Farmer review of the UK construction Labour model: Modernize or Die. [Online] available at http://www.constructionleadershipcouncil.co.uk/wp content/uploads/2016/10/Farmer-Review.pdf [Accessed: 11-12-19]

Gilbert, C., 2011. Prefabs - The Solution to a Housing Crisis. [Online] Available at: http://www.epsomandewellhistoryexplorer.org.uk/MoreOnPrefabs.pdf [Accessed 2206 2018].

Granger-Morton, M. (1997). Public Perception, Understanding, and Values. In The industrial Green Game. Washington DC: National Academy press. pp. 200-211.

HOME group. (2018) Public perceptions of modular homes not based on modular products [Online] Available at: https://www.homegroup.org.uk/Media/News/Home-Group-news/Public-perceptions-ofmodular-homes-not-based-on-modular-products [Accessed: 9/12/2019]

Hutchinson, T. (2013). Prefabricated housing can have benefits if done well. [Online], at https://www.theguardian.com/housing-network/2013/apr/04/prefab-housing-benefits-costs. [Accessed: 14-10-2019]

Luo, L.-z. (2015). "Risk factors affecting practitioners' attitudes toward the implementation of an industrialized building system: A case study from China." Engineering, Construction and Architectural Management 22(6): 622-643

MacFarlane, I. (2018). Ninety percent of public cannot identify a modular home. [Online] Available at https://www.showhouse.co.uk/news/90-of-public-cant-identify-a-modular-home [Accessed: 22-102019]

Mlecnik, E. (2013). Opportunities for supplier-led systemic innovation in highly energy-efficient housing. Journal of Cleaner production, Vol. 56, pp. 103-111.

Nanyam, V.P.S.N., Sawhney, A. and Gupta, P.A. (2017) Evaluating Offsite Technologies for Affordable Housing. Procedia Engineering, 196, 135-143.Rivera, L. (2017). Homes \& Property.

Steinhardt, D.A. and Manley, K. (2016) Adoption of prefabricated housing-the role of country context. Sustainable Cities and Society, 22, 126-135.

Švajlenka, J. and Kozlovská, M. (2018) Perception of User Criteria in the Context of Sustainability of Modern Methods of Construction Based on Wood. MDPI Sustainability, 10 (2).

Wu, G., Yang, R., Li, L., Bi, X., Liu, B., Li, S. and Zhou, S. (2019) Factors influencing the application of prefabricated construction in China: From perspectives of technology promotion and cleaner production. Journal of Cleaner Production, 219, 753-762. 